\title{
Noves dades sobre la distribució i l'estat de conservació de la falguera Dryopteris filix-mas (Dryopteridaceae) a les illes Balears
}

\author{
Xavier Manzano \\ Eva Moragues
}

Servei de Protecció d'Espècies. Conselleria d'Agricultura, Medi Ambient i Territori.

Govern de les Illes Balears

C/ Gremi de Corredors, 10, 1r pis (Polígon de Son Rossinyol). 07009 Palma de Mallorca xaviermanzano@terra.es

emoragues@dgcapea.caib.es

\section{Llorenç Sáez}

Universitat Autònoma de Barcelona. Unitat de Botànica

Facultat de Biociències. 08193 Bellaterra

llorens.saez@uab.cat

\section{Resum}

La falguera Dryopteris filix-mas és molt rara a les illes Balears, d'on es coneix únicament del nord de Mallorca (serra de Tramuntana). En el present estudi es revisen totes les dades disponibles sobre distribució, demografia i ecologia d'aquesta espècie amenaçada a les Balears, que qualifica per a la categoria IUCN «en perill crític». Actualment a Mallorca $D$. filix-mas existeix en una localitat, on és extremament escàs (un exemplar vegetatiu). D'altra banda, es discuteixen alguns aspectes que podrien explicar l'extrema raresa d'aquesta espècie a les illes Balears.

Paraules clau: relictes postglacials; distribució recent; plantes amenaçades.

Abstract. New data on the distribution and conservation status of the fern Dryopteris filix-mas (Dryopteridaceae) in the Balearic Islands

The fern species Dryopteris filix-mas is very rare in the Balearic Islands and currently only occurs in Northern Majorca (Serra de Tramuntana). This study reviews all available data on the distribution, demography and ecology of this endangered species in the Balearic Islands, which is classified in the IUCN "Critically endangered" category. In Majorca, $D$. filix-mas is currently present in a single locality, where it is extremely rare (one vegetative specimen). Furthermore, some aspects that could explain the extreme rarity of this species in the Balearic Islands are discussed.

Keywords: postglacial relict; recent distribution; threatened plants. 


\section{Introducció}

Els pteridòfits han constituït tradicionalment un grup de plantes especialment atractiu per als investigadors en disciplines com la biogeografia o la conservació de plantes amenaçades i, de fet, aquest grup de plantes vasculars acostuma a estar sobrerepresentat en els llistats d'espècies amenaçades (Wild et al., 2006). Aquesta particular situació també es constata a les illes Balears, on els pteridòfits són un dels grups més ben coneguts i que han estat objecte de diversos estudis i programes específics de conservació. Un dels gèneres de pteridòfits de les illes Balears que compta amb espècies d'interès conservacionista i biogeogràfic és Dryopteris adans, el qual compta amb tres espècies a l'arxipèlag: l'endemisme $D$. pallida subsp. balearica (Litard.) Fraser-Jenk., D. tyrrhena Fraser-Jenk. \& Reichst. i $D$. filix-mas (L.) Schott. El primer d'aquests tàxons és relativament freqüent a la serra de Tramuntana i també existeixen evidències de la seva presència, a mitjans del segle xx, a les muntanyes d'Artà, on no ha estat retrobat recentment (Sáez \& Rosselló, 2001). Per altra banda, les indicacions de D. pallida (Bory) C. Chr. ex Maire \& Petitm. subsp. pallida semblen ser referibles a exemplars que representen un extrem de la variabilitat de la subsp. balearica. Tant D. tyrrhena com $D$. filix-mas són actualment extremament rares a l'arxipèlag: la primera és una espècie difosa per muntanyes de la regió mediterrània occidental i que a les Balears està restringida a la zona culminal del Puig Major (Rosselló et al., 1989; Sáez \& Rosselló, 2001), mentre que D. filix-mas, que a les Balears es troba també al massís del Puig Major (Sáez \& Rosselló, 2001), té una distribució relativament àmplia, bàsicament circumboreal (Tryon \& Moran, 1997), tot i que és considerada com a eurosiberiana a Europa (Bolòs \& Vigo, 1984). Tant D. tyrrhena com D. filix-mas són considerades espècies amenaçades a les Balears (en els dos casos amb categoria «en perill crític», CR), però l'estat de conservació de les seves poblacions respon a situacions molt diferents: mentre que D. tyrrhena té una població petita i fortament restringida però aparentment estable des de fa un quart de segle, la situació de D. filix-mas es caracteritza per la seva extrema feblesa demogràfica i per una certa inestabilitat poblacional. De fet, actualment, es considera una espècie extingida en estat silvestre a les Balears. En el present treball, s'actualitza la informació relativa a aquesta darrera espècie, en relació amb el recent descobriment d'una nova localitat a les Balears.

\section{Material i mètodes}

En aquest treball es revisa la informació corològica detallada, la demografia i l'estat de conservació de D. filix-mas, sobre la base de dades obtingudes al camp en temps recents a les illes Balears. Per a cada localitat aportada s'indica un topònim de referència, el quadrat UTM $1 \times 1$ km (amb sistema de referències ED50), l'altitud i les principals característiques de l'hàbitat. Per establir-ne la categoria de risc en l'àmbit s'utilitzen els criteris IUCN (2001). 


\section{Resultats}

A continuació aportem dades sobre la distribució (Fig. 1), l'hàbitat i la demografia dels nuclis poblacionals de Dryopteris filix-mas a les illes Balears.

\section{Localitat 1: zona culminal del Puig Major}

En aquesta localitat, D. filix-mas fou descobert a finals de la dècada dels vuitanta del segle passat al Puig Major [31SDE8206]. Aquesta falguera estava restringida a una petita cavitat càrstica d'uns 3 m de fondària, situada a 1380 m d'altitud, en un vessant orientat al sud-est, en una zona en la qual també es troben altres espècies de pteridòfits rars a les Balears: Asplenium scolopendrium L., Dryopteris tyrrhena, Polystichum aculeatum (L.) Roth i P. setiferum (Forssk.) Woynar. Dins de la mateixa cavitat càrstica es trobaven 3 exemplars de $D$. filix-mas que creixien molt propers entre si (possiblement eren ramets [individus funcionals en un organisme clonal]), dos dels quals eren reproductius i de mida relativament grossa (frondes de fins a 1,3 m de longitud). Aquests exemplars no eren accessibles per a les cabres assilvestrades que a mitjans dels anys noranta van començar a incrementar les seves poblacions a la serra de Tramuntana, posant en perill algunes de les espècies de falgueres abans indicades.

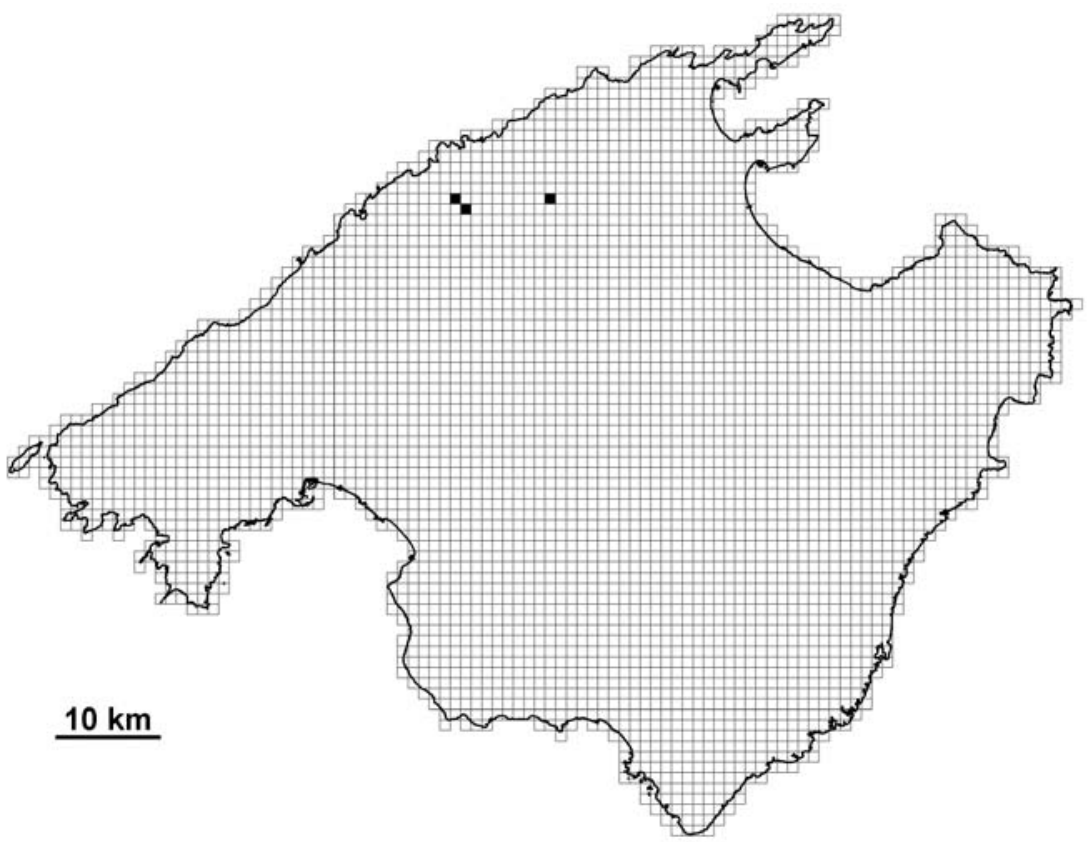

Figura 1. Distribució de Dryopteris filix-mas a Mallorca (illes Balears) en quadrats UTM d' $1 \times 1 \mathrm{~km}$. 
Aquest nucli poblacional del Puig Major, que és l'únic del qual hi ha evidències que hagi comptat amb exemplars reproductius, va desaparèixer a mitjans de la darrera dècada del segle passat per causes desconegudes. Afortunadament, des del Jardí Botànic de Sóller es va aconseguir preservar un exemplar que actualment es conserva viu en aquesta institució, i a partir del qual s'han iniciat actuacions de reintroducció a la zona culminal del Puig Major gràcies a la col·laboració del Viver Forestal de les Illes Balears (Menut) i l'actuació del Servei de Protecció d'Espècies. Tot i que és necessari un cert temps per avaluar el resultat d'aquesta recent reintroducció (any 2011), actualment (novembre del 2013) no se'n coneix cap exemplar (ni vegetatiu ni reproductiu) de D. filix-mas al Puig Major.

\section{Localitat 2: serra de Na Plana}

El juliol de 1989 un de nosaltres (L.S.) va localitzar un exemplar vegetatiu de mida petita (frondes d'uns $20 \mathrm{~cm}$ ) a la serra de Na Plana [31SDE8305], a uns 930 m s.n.m., en una zona que, com l'anterior, presenta un intens modelat càrstic. L'únic pteridòfit que es trobava a la zona propera és $D$. pallida subsp. balearica. A diferència del nucli poblacional del Puig Major, l'exemplar de D. filix-mas creixia en una fissura de roca calcària compacta en una zona bastant exposada (poc ombrívola, amb micro-orientació sud-est), i presentava diverses frondes de mida petita, totes vegetatives, i amb indicis de patir una forta predació per cabres assilvestrades. Aquest exemplar no ha tornat a ser observat en posteriors prospeccions (mitjans dels anys noranta) a la zona.

\section{Localitat 3: Es Castellot}

A mitjans de juliol de 2013 un de nosaltres (X.M.) va observar un nou exemplar al vessant nord-occidental des Castellot, a la capçalera del torrent de Ses Figueroles [31SDE9106], a 580 m s.n.m. Posteriorment, vam visitar novament la zona i vam recol-lectar-ne una fulla com a testimoni d'herbari (29-VII-2013, X. Manzano \& L. Sáez [L. Sáez herb. pers]). En aquesta nova localitat, relativament allunyada de les dues anteriors, D. filix-mas presenta un comportament epífit, ja que creix en una ramificació del tronc principal d'un exemplar de Pinus halepensis (Fig. 2). La vegetació de la zona correspon a una garriga de muntanya amb estrat arbori poc dens de $P$. halepensis, i en uns penyals propers es troben altres pteridòfits de caràcter ben poc higròfil: Asplenium onopteris L. i A. sagittatum (DC.) Bange. L'únic exemplar de D. filix-mas és vegetatiu i presenta només 4 frondes, totes elles de mida petita (menys de $25 \mathrm{~cm}$ de longitud). Vora l'exemplar de D. filix-mas, i també sobre el tronc P. halepensis, creix l'endemisme Rubia balearica (Willk.) Porta i alguns briòfits epífits: Frullania dilatata (L.) Dumort. i Hypnum cupressiforme Hedw. var. cupressiforme.

Sobre la base de les dades actuals, la categoria de risc de D. filix-mas a les Balears, segons criteris IUCN (2001) seria assimilable a la de «en perill crític» (CR), segons els criteris següents: A2a,B1ab(i,ii,iv,v)+2ab(i,ii,iv,v),C2a(i),D ja que: 


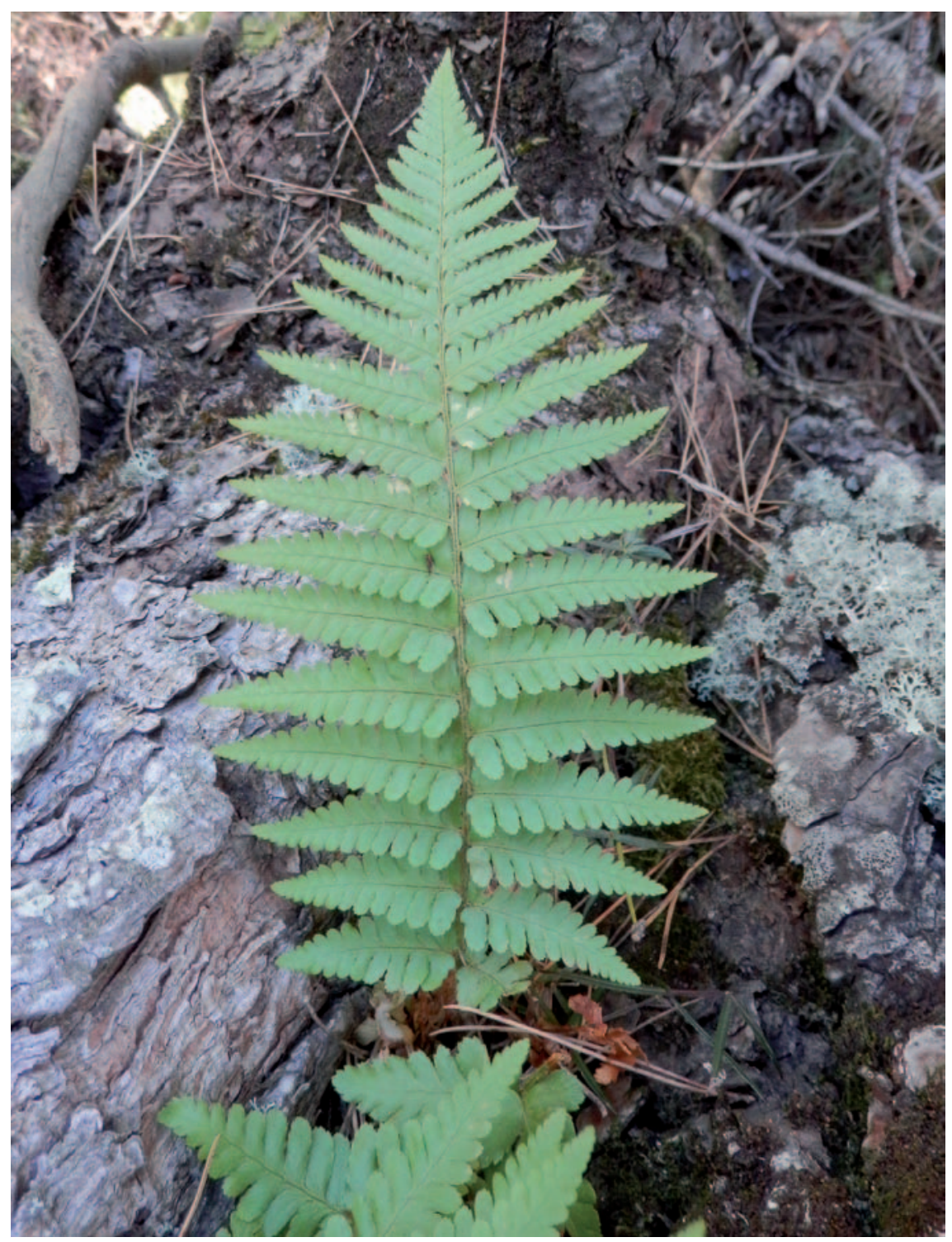

Figura 2. Exemplar de Dryopteris filix-mas del torrent de Ses Figueroles. Fotografia: Llorenç Sáez. 
1) [criteri A]: s'ha constatat una reducció de la població (mitjançant observacions directes) $\geq 80 \%$ en el període indicat per IUCN (2001).

2) [criteri B]: actualment només es coneix d'una localitat (extensió de la presència $<100 \mathrm{~km}^{2} \mathrm{i}$ àrea d'ocupació estimada $<10 \mathrm{~km}^{2}$ ) i s'ha observat en els darrers anys una disminució contínua en: extensió de la presència estimada, àrea d'ocupació, nombre de localitats o subpoblacions i nombre d'individus madurs.

3) $[$ Criteri $\mathrm{C}]$ : mida poblacional de només un exemplar vegetatiu (restringit a la localitat 3), i que pel moment és dubtós que pugui ser potencialment reproductiu en un futur immediat. A més, s'ha constatat una disminució en el nombre d'exemplars reproductius, i cap població té més de 50 exemplars madurs.

4) [Criteri D]: la mida de la població actual no assoleix el límit establert en aquest criteri per IUCN (2001).

\section{Discussió}

Diversos autors han suggerit l'existència a les zones altes de la serra de Tramuntana de boscos caducifolis o de caràcter mesòfil en temps anteriors als actuals (Rosselló \& Ginés, 1980; Fiol, 1995; Rita, 1998a, b; Alcover et al., 2000). Aquest tipus de vegetació hauria desaparegut per factors climàtics, edàfics o bé antròpics. Tot i la desaparició generalitzada d'aquesta vegetació de caràcter nemoral a la muntanya mallorquina, actualment existeixen diversos elements que possiblement tinguin un caràcter relictual, com seria el cas de diverses espècies de falgueres de la família Dryopteridaceae, entre les quals es troba D. filix-mas, així com Polystichum aculeatum i $P$. setiferum. Aquestes tres espècies presenten unes característiques vegetatives molt semblants entre elles, i a més els seus requeriments ecològics són relativament prou comparables entre si tant a Mallorca com a zones properes de la península Ibèrica, i, a més, coincideixen en una mateixa localitat de Mallorca (zona culminal del Puig Major), on creixen al mateix tipus d'hàbitats (encletxes profundes $\mathrm{i}$ cavitats càrstiques amb un microclima peculiar d'ombra $\mathrm{i}$ humitat elevada). Aquestes depressions del terreny i encletxes de cavitats càrstiques de muntanya han estat indicades com un dels principals ambients de refugi per a espècies de caràcter nemoral, tant pel que fa a les plantes vasculars com als briòfits (Pérez-Obiol et al., 2003).

Hi ha indicis de la declinació poblacional (a Mallorca) d'aquestes espècies de falgueres de caràcter nemoral, en especial de $P$. setiferum, que hauria desaparegut de diverses zones on era present a mitjans del segle Xx, com és el cas de la zona de Cal Reis, el Gorg Blau o del Puig de Massanella. És destacable que tant en el cas de $P$. setiferum com en el de $P$. aculeatum, espècies que tot i la seva extrema raresa i feblesa demogràfica compten amb un nombre d'efectius molt més alt (centenars d'exemplars en el cas de $P$. setiferum) del que es coneix per a D. filix-mas, no s'hagi documentat mai el descobriment de nous nuclis poblacionals demogràficament inestables, a diferència del que s'ha constatat amb aquesta darrera espècie. Les possibles explicacions a aquest fet poden ser diverses, i entre 
aquestes una podria suposar que aquestes tres localitats conegudes de D. filix-mas siguin els darrers reductes d'una espècie en situació evident de forta declinació poblacional.

Una segona explicació es relacionaria amb l'existència d'un banc d'espores més o menys persistent, com han suggerit alguns autors (Dyer \& Lindsay, 1992); però per les característiques de les zones on s'ha observat D. filix-mas a les Balears (encletxes rocoses, fissures de roques i troncs d'arbres) aquesta explicació no sembla ser massa versemblant.

Una altra possibilitat seria que en alguna(es) localitat(s) de la serra de Tramuntana existeixi un o diversos nuclis poblacionals de D. filix-mas que fins al moment hagin passat desapercebuts i que comptin amb exemplars reproductors, a partir dels quals es produeixen nous intents de colonització en alguns punts de la serralada. No obstant això, aquesta dada no es verifica per a espècies amb unes característiques vegetatives i ecològiques molt semblants a les de D. filix-mas, com és el cas de $P$. setiferum i de $P$. aculeatum, les quals tenen una mida poblacional més important $\mathrm{i}$ una producció regular de frondes fèrtils cada any.

D'altra banda, tot i que certament és molt probable que D. filix-mas sigui un representant d'aquesta flora de caràcter nemoral anterior a l'actual vegetació de la muntanya mallorquina, tampoc no es pot descartar que la inestabilitat poblacional detectada sigui deguda, si més no en algunes de les localitats menys favorables per al desenvolupament d'aquesta espècie, a colonitzacions a molt llarga distància. S'ha documentat que un exemplar reproductiu de $D$. filix-mas produeix fins a 100 milions d'espores cada any (Cousens, 1988), però estudis realitzats en condicions controlades indiquen que la majoria de les espores d'aquesta espècie es dispersen només fins a una distància de 14 cm de la planta mare (Schneller, 1995). Per altra banda, i en relació amb eventuals esdeveniments de colonització, s'ha posat de manifest que $D$. filix-mas presenta, en general, gametòfits hermafrodites (amb anteridis i arquegonis) (Korpelainen, 1994). Això fa possible una autofecundació intragametofítica que pot ser molt útil en condicions de feblesa poblacional o bé en esdeveniments de colonització (Korpelainen, 1994).

Algunes d'aquestes diferents interpretacions sobre la presència de petits nuclis poblacionals demogràficament inestables de $D$. filix-mas a les Balears no són excloents entre si, i el tema hauria de ser estudiat més profundament. En qualsevol cas, convé refinar la informació sobre la distribució i els requeriments ecològics de D. filix-mas a les Balears, i tenir en consideració aquests aspectes biològics abans comentats en el disseny de les diferents actuacions de conservació (in situ i ex situ) que es desenvolupen fins al moment sobre aquesta espècie a l'arxipèlag.

\section{Referències bibliogràfiques}

Alcover, J.A.; Llabrés, M.; Moragues, L. 2000. Les Balears abans dels humans. Monografies de la Societat d'Història Natural de les Balears 8. Sa Nostra-SHNB. Ciutat de Mallorca.

Bolòs, O. \& J. Vigo. 1984. Flora dels Països Catalans. Vol. 1. Barcelona: Barcino. 
Cousens, I. 1988. Reproductive strategies of Pteridophytes. In: Lovett Doust, J.; Lovett Doust, L. (Eds.). Plant Reproductive Ecology. Patterns and Strategies: 307-325. Oxford University Press.

Dyer, A.E.; Lindsay, S. 1992. Soil spore banks of temperate ferns. Amer. Fern. J. 82: 89122.

Fiol, L. 1995. La flora de les entrades de les cavitats de Mallorca. Monogr. Soc. Hist. Nat. Balears 3:145-153.

IUCN 2001. IUCN Red List Categories: Version 3.1. IUCN Species Survival Commission. IUCN, Gland \& Cambridge.

Korpelainen, H. 1994. Growth, sex determination and reproduction of Dryopteris filix-mas (L.) Schott gametophytes under varying nutritional conditions. Bot. J. Linn. Soc. 114: 357-366.

Pérez-Obiol, R.; Sáez, L.; Yll, E.I. 2003. Vestigis florístics postglacials a les illes Balears i dinàmica de la vegetació holocènica. Orsis 18: 77-94.

Rita J. 1998a. Els pisos de vegetació de la serra de Tramuntana. In: Tolosa F. (Ed.). La serra de Tramuntana, aportacions per a un debat: 59-69. Palma de Mallorca: Sa Nostra.

Rita J. 1998b. La cobertora vegetal. In: Blázquez, M.; Díaz, R.; Rullan, O. (Eds.). La serra de Tramuntana, natura i cultura: 39-50. Palma de Mallorca: Moll.

Rosselló, J.A.; Ginés, A. 1980. Introducció a la brioflora dels avencs mallorquins. Endins 7: 27-35.

Rosselló, J.A.; Gradaille, J.L.; Sastre, B.; Vicens, J.; Salvo, A.E. 1989. Dryopteris tyrrhena Fraser-Jenk. \& Reichstein en Baleares. Notas pteridológicas 21. Acta Bot. Malacitana 14: 255-258.

Sáez, L.; Rosselló, J.A. 2001. Llibre vermell de la flora amenaçada de les illes Balears. Conselleria de Medi Ambient. Govern de les Illes Balears. Palma de Mallorca.

Schneller, J.J. 1995. Aspects of spore release of Asplenium ruta-muraria with reference to some other woodland ferns: Athyrium filix-femina, Dryopteris filix-mas, and Polystichum aculeatum. Botanica Helvetica 105(2): 87-197.

Tryon, A.F.; Moran, R.C. 1997. The Ferns and Allied Plants of New England. Center for Biological Conservation, Massachusetts Audubon Society, Lincoln, Massachusetts.

Wild, M.; Gagnon, D.; Bouchard, A. 2006. Why are ferns regularly over-represented ons state and provincial rare list plants? Diversity and Distributions 12: 749-755. 